\title{
Association of the CD226 (DNAM-1) Gly307Ser polymorphism with juvenile idiopathic arthritis
}

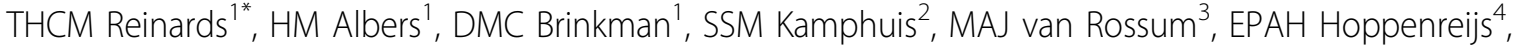 \\ HJ Girschick ${ }^{5}$, C Wouters ${ }^{6}$, RK Saurenmann ${ }^{7}$, JJ Houwing-Duistermaat ${ }^{1}$, REM Toes ${ }^{1}$, TWJ Huizinga ${ }^{1}$, R ten Cate ${ }^{1}$, \\ MW Schilham ${ }^{1}$
}

From 18th Pediatric Rheumatology European Society (PReS) Congress

Bruges, Belgium. 14-18 September 2011

\section{Background}

Recent genetic studies have reported an association of the Gly307Ser single nucleotide polymorphism (SNP) in the CD226 gene with susceptibility to multiple autoimmune diseases. CD226 or DNAM-1 is a type 1 membrane protein belonging to the Ig-superfamily and is involved in the adhesion and co-stimulation of T cells and NK cells. A trend towards association of this SNP with Juvenile Idiopathic Arthritis (JIA) was recently reported, but was not statistically significant $(\mathrm{p}=0.13)$ (Genes Immun. 2010 Mar;11(2):194-8).

\section{Aim}

We performed a case-control genetic association study to investigate whether $C D 226$ Gly307Ser is associated with susceptibility to JIA.

\section{Methods}

CD226 Gly307Ser was genotyped in 667 JIA cases and 1320 healthy controls, both of North-West-European white origin. Allele frequencies were compared. Patients with oligoarticular (persistent and extended), polyarticular (rheumatoid factor negative and positive) and systemic JIA have been included and were analyzed separately as well as grouped together. A meta-analysis of our study combined with the previously published study was performed. analysis (of all subtypes grouped together) confirmed the association with JIA ( $\mathrm{p}=0.003, \mathrm{OR}=1.14,95 \% \mathrm{CI}$ : 1.05-1.23).

\section{Conclusion}

This study provides evidence for a novel JIA susceptibility locus. Additionally, a subtype-specific association of CD226 with persistent oligoarticular JIA has been identified. This finding is in line with the hypothesis that this oligoarticular subtype is not only phenotypically, but also genetically different from the polyarticular subtypes, including extended oligoarthritis.

\section{Author details \\ ${ }^{1}$ Leiden University Medical Center, Leiden, The Netherlands. ${ }^{2}$ Erasmus Medical Center, Rotterdam, The Netherlands. ${ }^{3}$ Academic Medical Center, Amsterdam, The Netherlands. ${ }^{4}$ Radboud University Medical Center, \\ Nijmegen, The Netherlands. ${ }^{5}$ University of Würzburg, Würzburg, Germany. ${ }^{6}$ University Hospital Gasthuisberg, Leuven, Belgium. 'University Children's Hospital, Zürich, Switzerland.}

Published: 14 September 2011

doi:10.1186/1546-0096-9-S1-P286

Cite this article as: Reinards et al:: Association of the CD226 (DNAM-1) Gly307Ser polymorphism with juvenile idiopathic arthritis. Pediatric Rheumatology 2011 9(Suppl 1):P286.

\section{Results}

CD226 Gly307Ser was significantly associated with susceptibility to JIA ( $\mathrm{p}=0.002, \mathrm{OR}=1.23,95 \%$ CI: 1.08-1.41), particularly in the persistent oligoarticular subtype $(\mathrm{p}=0.0008, \mathrm{OR}=1.38,95 \%$ CI: $1.14-1.67)$. The meta-

\footnotetext{
* Correspondence: t.h.c.m.reinards@lumc.n

${ }^{1}$ Leiden University Medical Center, Leiden, The Netherlands

Full list of author information is available at the end of the article
}

(c) 2011 Reinards et al; licensee BioMed Central Ltd. This is an open access article distributed under the terms of the Creative Commons 